\title{
Adenosine-generating ovarian cancer cells attract myeloid cells which differentiate into adenosine-generating tumor associated macrophages - a self- amplifying, CD39- and CD73-dependent mechanism for tumor immune escape
}

Itsaso Montalbán del Barrio ${ }^{1,2}$, Cornelia Penski ${ }^{3,4}$, Laura Schlahsa', Roland G. Stein ${ }^{1}$, Joachim Diessner ${ }^{1}$, Achim Wöckel ${ }^{1}$, Johannes Dietl ${ }^{1}$, Manfred B. Lutz ${ }^{5}$, Michel Mittelbronn ${ }^{3,4}$, Jörg Wischhusen ${ }^{1 * \dagger}$ (D) and Sebastian F. M. Häusler ${ }^{1 * \dagger}$

\begin{abstract}
Background: Ovarian cancer (OvCA) tissues show abundant expression of the ectonucleotidases CD39 and CD73 which generate immunomodulatory adenosine, thereby inhibiting cytotoxic lymphocytes. Little, however, is known about the effect of adenosine on myeloid cells. Considering that tumor associated macrophages (TAM) and myeloidderived suppressor cells (MDSC) constitute up to $20 \%$ of OvCA tissue, we investigated the effect of adenosine on myeloid cells and explored a possible contribution of myeloid cells to adenosine generation in vitro and ex vivo.

Methods: Monocytes were used as human blood-derived myeloid cells. After co-incubation with SK-OV-3 or OAW-42 OvCA cells, monocyte migration was determined in transwell assays. For conversion into M2-polarized "TAMlike" macrophages, monocytes were co-incubated with OAW-42 cells. Ex vivo TAMs were obtained from OvCA ascites. Macrophage phenotypes were investigated by intracellular staining for IL-10 and IL-12. CD39 and CD73 expression were assessed by FACS analysis both on in vitro-induced TAM-like macrophages and on ascites-derived ex situ-TAMs. Myeloid cells in solid tumor tissue were analyzed by immunohistochemistry. Generation of biologically active adenosine by TAM-like macrophages was measured in luciferase-based reporter assays. Functional effects of adenosine were investigated in proliferation-experiments with $\mathrm{CD}^{+} \mathrm{T}$ cells and specific inhibitors.

Results: When CD39 or CD73 activity on OvCA cells were blocked, the migration of monocytes towards OvCA cells was significantly decreased. In vivo, myeloid cells in solid ovarian cancer tissue were found to express CD39 whereas CD73 was mainly detected on stromal fibroblasts. Ex situ-TAMs and in vitro differentiated TAM-like cells, however, upregulated the expression of CD39 and CD73 compared to monocytes or M1 macrophages. Expression of ectonucleotidases also translated into increased levels of biologically active adenosine. Accordingly, co-incubation with these TAMs suppressed CD4 ${ }^{+} \mathrm{T}$ cell proliferation which could be rescued via blockade of CD39 or CD73. (Continued on next page)
\end{abstract}

\footnotetext{
*Correspondence: Wischhusen_J@ukw.de; Haeusler_S@ukw.de

${ }^{\dagger}$ Equal contributors

'Department of Obstetrics and Gynaecology, University of Würzburg, School

of Medicine, Josef-Schneider-Strasse 4, 97080 Würzburg, Germany

Full list of author information is available at the end of the article
} 


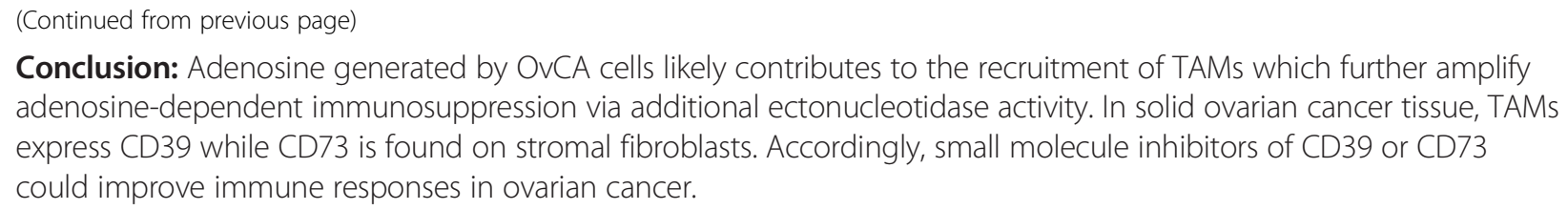

Keywords: Ovarian cancer, Adenosine, CD39, CD73, Tumor associated macrophages, Immune escape

\section{Background}

Immune function in the tumor microenvironment is shaped by tissue-specific and tumor-derived signals [1] which often decrease the effectiveness of anti-tumor immune responses. This is particularly relevant for malignancies like ovarian cancer (OvCA) where immunological processes like infiltration with cytotoxic [2] or regulatory $\mathrm{T}$ cells $\left(\mathrm{T}_{\mathrm{reg}}\right)[3]$ heavily affect the prognosis $[1,4,5]$. In this context, we and others have identified tumor-derived adenosine as important immunomodulatory factor [6-10]. Adenosine which signals via four specific receptors [11, 12] can activate several cellular responses which mainly serve to protect the tissue from excessive inflammatory responses [12-16]. Sustained high levels of adenosine can, however, turn harmful by triggering immune suppression or by activating unremitting wound-healing [17, 18]. Adenosine levels are thus kept low under physiological conditions, but increased by stimuli such as inflammation, trauma, hypoxia or ischemia [12]. In ovarian cancer, high levels of adenosine are due to tumor-specific expression of the ectonucleotidases CD39/ENTPD1 and CD73/ecto-5' nucleotidase [7] which synergistically catalyze the degradation of extracellular immune-stimulatory ATP to immune-inhibitory adenosine. First, ATP or ADP are hydrolysed by CD39 to AMP which in turn is dephosphorylated to adenosine by CD73 [19-22]. Adenosine can then suppress anti-tumoral functions of $\mathrm{CD}_{4}^{+}$or $\mathrm{CD}^{+} \mathrm{T}$ cells and Natural Killer (NK) cells [7, 9]. This mechanism of immunosuppression was also proposed for $\mathrm{CD}^{+}{ }^{+} \mathrm{CD} 25^{+} \mathrm{FoxP}^{+}{ }^{+} \mathrm{T}_{\text {reg }}$ cells [20]. OvCA cells, however, seem to greatly outperform $\mathrm{T}_{\text {reg }}$ regarding adenosine generation [7].

Myeloid-derived suppressor cells (M-MDSC) and tumor associated macrophages (TAM) are infiltrating myeloid cells which, similar to $T_{\text {reg }}$, significantly impact survival as they enhance progression and metastasis [23-26]. In ovarian cancer they build up to $20 \%$ of the tumor volume [27]. Monocytic and polymorphonuclear MDSC are recruited by tumors where they can remain in their relatively immature state. The tumor microenvironment, however, promotes further differentiation of monocytic MDSC into TAM [28, 29]. TAM are alternatively activated M2-macrophages which (as opposed to inflammatory M1-macrophages) orchestrate anti-inflammatory, mostly immunosuppressive reactions
$[25,30]$. By producing reactive oxygen species (ROS), nitric oxide (NO), indoleamine-2,3-dioxygenase (IDO) and by secreting high levels of immunosuppressive cytokines like IL-10 and TGF- $\beta$ [27], MDSC and TAM significantly shape the immune contexture of ovarian and other solid tumors. Clinically, abundance of MDSC and TAM has been linked to poor outcome in various malignancies $[31,32]$ including ovarian cancers of the serous and mucinous subtype [33, 34]. Interestingly, myeloid cells seem to accumulate in hypoxic tissue areas [27, 31] where low oxygen pressure leads to necrotic cell death with concomitant ATP release. CD39 and CD73 can, however, convert this pro-inflammatory signal [35-38] into immunosuppressive adenosine.

While the suppressive effect of adenosine on several immune cells such as $\mathrm{CD}^{+}$and $\mathrm{CD} 8^{+} \mathrm{T}$ cells and Natural Killer (NK) cells is well documented, little is known about the effect of tumor-derived adenosine on myeloid cells. Moreover, the available data are all based on murine cells [39-41].

These findings prompted us to investigate the effect of OvCA-derived adenosine on human monocytes which are the circulating precursors of both monocytic MDSC and TAM and can be obtained from peripheral blood. In addition, we explored a possible regulation of CD39 and CD73 expression on macrophages in response to the respective mode of differentiation. Finally, we also performed proliferation assays in vitro in order to functionally confirm an immunomodulatory role of CD39 and CD73 on M2macrophages (or TAM). Within the limits of an ex vivo study confined to the use of PBMC-derived monocytes to approximate MDC and TAM, we have thereby obtained data that suggest a role for adenosine in the accumulation and function of tumor-associated macrophages.

\section{Methods \\ Bioinformatic analysis}

Gene expression data were obtained from from 285 ovarian cancer samples, from the AOCS (Australian Ovarian Cancer Study) (GEO ID: GSE9891). Gene expression was profiled on the affymetrix U133_plus2 platform. Expression data are publicly available from the R2 bioinformatics program (http://R2.amc.nl). Bioinformatic analysis of microarray data was conducted with the R2 tool by first searching for genes correlated with CD39 in 
ovarian cancer. Subsequently, pairwise correlation analyses were performed as indicated. To correlate expression of CD39 and CD73 with overall survival inovarian cancer patients, we have used the the free online tool KaplanMeier plotter (http://kmplot.com/analysis/index.php?p= service\&cancer=ovar) [42]. 347 patients with stage 3 and 4 (high-grade) serous ovarian cancer were included, regardless of p53 status, CA125 levels, optimal/suboptimal debulking or chemotherapy. A combined classifier comprising gene expression data for both CD39/ ENTPD1 (Affymetrix ID 228585) and CD73/NT5E (Affymetrix ID 203939) was bioinformatically computed and survival probabilities were calculated according to Kaplan-Meier statistics including $95 \%$ confidence intervals (CIs). For comparison, two-sided log-rank tests were used.

\section{Immunohistochemistry and immunofluorescence}

All tissue specimens (10 ovarian cancer, one healthy ovary) were provided by the University Hospital Würzburg (Würzburg, Germany). Samples had been evaluated by at least two pathologists in routine diagnostics as serouspapillary OvCA or benign ovary. All human tissue specimens were cut with a microtome ( $3 \mu \mathrm{m}$ thickness) and placed on SuperFrost-Plus slides (Microm International, Walldorf, Germany). IgG2a-mouse-anti-human CD39 antibody (dilution 1:10; Biozol, Eching, Germany) and IgG-rabbit-anti-human CD73 antibody (dilution 1:500; Sigma-Aldrich, St. Louis, MO, USA) were used for immunohistochemistry. Tissue labelling was performed using the DiscoveryXT immunohistochemistry system (Ventana/Roche, Strasbourg, France). After a cell conditioning pre-treatment a $4 \mathrm{~min}$ blocking step was performed. The primary antibodies were applied for $32 \mathrm{~min}$, followed by a secondary OmniMap anti-mouse HRP (horseradish peroxidase) (Ventana) for 16 min incubation for anti-CD39 staining and a universal secondary HRP antibody (Ventana) for $32 \mathrm{~min}$ for anti-CD73 staining. For diaminobenzidine (DAB) visualization, the sections were incubated with one drop of DAB CM and one drop of $\mathrm{H}_{2} \mathrm{O}_{2} \mathrm{CM}$ (Ventana) for $8 \mathrm{~min}$, followed by incubation with a copper enhancer (Ventana) for $4 \mathrm{~min}$. Human tonsil (for anti-CD39) and human placenta (for anti-CD73) were used as positive controls. Negative controls were performed by omission of the first antibody. Finally, all sections were then washed, counterstained with hematoxylin and mounted.

For immunofluorescent stainings, $3 \mu \mathrm{m}$ thick slides were deparaffinized with xylene and rehydrated in a descending alcohol sequence. Heat pre-treatment for antigen retrieval was performed with citrate buffer $(\mathrm{pH}$ 6.0) for $40 \mathrm{~min}$, followed by a blocking step for $30 \mathrm{~min}$ (Roti-Immuno Block, dilution 1:10; Roth, Karlsruhe, Germany) at room temperature. Sections were incubated with primary antibodies for $1 \mathrm{~h}$ at room temperature
(anti-CD39: dilution 1:10 and anti-CD73: dilution 1:500) and subsequently labelled with secondary antibodies for 1 h each (for CD39: Alexa Fluor488, dilution 1:250, donkey anti-mouse IgG, Invitrogen, Darmstadt, Germany; for anti-CD73: Alexa Fluor488, dilution 1:250, goat anti-rabbit IgG, Invitrogen). Next, the primary antibodies for the double staining were added for $1 \mathrm{~h}$ at room temperature (for anti-CD39: rabbit-anti-human-Iba-1 (dilution 1:1000; Wako, Richmond, VA, USA; for anti-CD73: mouse-anti-human-CD68 (dilution 1:500; Dako, Hamburg, Germany), followed by an additional secondary antibody for $1 \mathrm{~h}$ (for anti-Iba1: Alexa Fluor568, dilution 1:250, donkey anti-rabbit IgG, Invitrogen; for anti-CD68: Alexa Fluor568, dilution 1:250, goat anti-mouse IgG, Invitrogen). Nuclear counterstaining was performed using Topro-3 (dilution: 1:1000; Invitrogen) followed by sudan black for 5 min to block autofluorescence. Fluorescence images were analyzed and recorded on a Nikon C1si (Nikon, Japan) confocal microscope, using the EZ-C1 software. After recording, digital images were further processed and adjusted for brightness, contrast and color balance.

\section{Cell culture}

The human ovarian cancer cell lines SK-OV-3 or OAW42 were cultured in RPMI 1640 medium with 10 \% FCS, $0.02 \%$ sodium pyruvate, penicillin $(100 \mathrm{IU} / \mathrm{ml})$ and streptomycin $(100 \mu \mathrm{g} / \mathrm{ml})$ (all from Gibco, Karlsruhe, Germany). Cell line identity was confirmed via single tandem repeat fingerprinting by the Deutsche Sammlung für Mikroorganismen und Zellkulturen (Braunschweig, Germany). Tumor associated macrophages were isolated from ascites from OvCA patients $(n=9)$ using antiCD14 coated magnetic beads (Miltenyi Biotec, Bergisch Gladbach, Germany) according to the manufacturer's recommendations. For control purposes peritoneal macrophages were isolated from patients with benign ascites $(n=8)$. All ascitic fluid punctures were performed for medical needs.

\section{Migration assay}

Peripheral blood mononuclear cells (PBMC) were isolated from the blood of healthy volunteers. To enrich for monocytes, a two-step gradient centrifugation protocol was used, starting with a standard Ficoll-based separation medium (Biocoll, Biochrom, Berlin, Germany) followed by a Percoll gradient (Easycoll separation medium, Biochrom, Berlin, Germany). 500.000 monocytes per well were then placed in the upper inserts of 24-well Transwell plates (pore diameter $8 \mu \mathrm{m}$, membrane thickness $10 \mu \mathrm{m}$, cell growth area $0.33 \mathrm{~cm}^{2}$, Corning, Tewksbury, USA) while 200.000 OAW-42 or SK-OV-3 cells were placed in the corresponding compartments at the bottom of the plate. All assays were conducted in RPMI 1640 medium with $5 \%$ human $\mathrm{AB}$ serum (PAA) $(500 \mu \mathrm{l}$ per well). 
After an incubation period of $6 \mathrm{~h}$, all cells from the bottom plates were analyzed by flow cytometry. Monocytes were identified with anti CD11c-FITC (Immunotools, Friesoythe, Germany) whereas OvCA cells were stained with EpCam-APC (BioLegend, San Diego, USA) (both antibodies used at 1:100 dilution). Dead cells were excluded via co-staining with 7 -aminoactinomycin $\mathrm{D}$. To quantify the relative migration rate, a standard curve was generated from several samples containing $2 \times 10^{5}$ cancer cells together with different numbers of monocytes $\left(0-10^{6}\right.$ cells). To block CD39 or, respectively, CD73 activity during the transwell co-culture, ARL $67156(250 \mu \mathrm{M}$, Tocris, Bristol, UK), $\alpha, \beta$-methyleneadenosine- 5 '-diphosphate ("APCP", $100 \mu \mathrm{M}$, Sigma, Deisenhofen, Germany) or appropriate solvent controls were used (Crack et al., 1995; Krug et al., 1973). As positive control, the metabolically stable adenosine receptor agonist adenosine- $5^{\prime}$ $\mathrm{N}$-ethylcarboxamide (NECA, Tocris) was employed at 100 $\mathrm{nM}$. To control for effects of adenosine on chemokinesis, a control without tumor cells but with equal amounts of NECA in both compartments was performed.

\section{$\mathrm{RT}^{2}$ Profiler PCR array for adenosine-dependent modulation of chemokines and chemokine receptors on monocytes}

To investigate if NECA has an effect on the expression of chemokines or chemokine receptors in monocytes, mRNA expression on $\mathrm{CD}_{14} 4^{+}$bead-purified monocytes was assessed $3 \mathrm{~h}$ after NECA treatment in comparison to an untreated control. 280ng total RNA per sample were used for cDNA synthesis ( $\mathrm{RT}^{2}$ First Strand Kit, Qiagen, Hilden, Germany). The $\mathrm{RT}^{2}$ Profiler PCR array for human chemokines \& receptors and the $\mathrm{RT}^{2}$ SYBR Green ROX qPCR mastermix (both from Qiagen) were used according to the manufacturer's instructions. Assays were run on a StepOnePlus RealTime-PCR cycler (thermofisher, Darmstadt, Germany). For data analysis, the same threshold was applied for each plate and data were analyzed in the Qiagen Analysis Webportal. Candidate molecules appearing to be regulated by NECA in the arrays where then validated by qRT-PCR (Additional file 1).

\section{Determination of M1 and M2 macrophage polarization and of CD39 and CD73 expression}

Monocytes were isolated from healthy volunteers as described above and matured in Lumox dishes (Greiner bio-one, Frickenhausen, Germany) during 7 days in RPMI 1640 with $5 \%$ human $\mathrm{AB}$ serum at $37{ }^{\circ} \mathrm{C}$. Polarization towards M1-phenotype was induced with human recombinant IFN- $\gamma[1 \mu \mathrm{g} / \mathrm{ml}]$ and LPS $[10 \mu \mathrm{g} / \mathrm{ml}]$ (both from Peprotech, Hamburg, Germany) for $48 \mathrm{~h}$ at $37^{\circ} \mathrm{C}$ in RPMI 1640 medium with $5 \%$ human $\mathrm{AB}$ serum. M2-phenotype macrophages were generated by co-culture of matured monocytes with OAW-42 cells in transwell plates (pore size $1 \mu \mathrm{m}$ ) for $48 \mathrm{~h}$ at $37^{\circ} \mathrm{C}$ in RPMI 1640 with $5 \%$ human AB serum [43]. M1- and M2-polarization were confirmed by flow cytometric analysis of intracellular IL-10- and IL12-levels [44]; to this aim the cells were stained with antiIL10-FITC (Miltenyi) and anti-IL12-APC (Biolegend) at 1:100 dilution. Based on the expression of CD68, macrophage purity was found to be $>90 \%$. In addition, arginase activity was determined in a colorimetric assay based on urea production. Polarized macrophages were washed twice with ice-cold PBS, scraped and centrifuged at 1,200 $\mathrm{rpm}$ for $5 \mathrm{~min}$. Cell pellets were resuspended into $200 \mu \mathrm{l}$ lysis buffer (50 mM Tris- $\mathrm{HCl}$ (pH 7.5), $0.1 \mathrm{mM}$ EDTA, $0.1 \mathrm{mM}$ ethylene glycol-bis( $\beta$-aminoethyl ether)- $N, N, N^{\prime}$, $N^{\prime}$-tetraacetic acid, $1 \mathrm{mM}$ dithiothreitol, $1 \mu \mathrm{g} / \mathrm{ml}$ leupeptin, $1 \mu \mathrm{g} / \mathrm{ml}$ aprotinin, and $0.1 \mathrm{mM}$ phenylmethylsulfonyl fluoride). Cell lysates $(50 \mu \mathrm{l})$ were added into $50 \mu \mathrm{l}$ of $50 \mathrm{mM}$ Tris- $\mathrm{HCl}(\mathrm{pH} 7.5)$ containing $10 \mathrm{mM} \mathrm{MnCl}$. Arginase was then activated by heating the mixture at $55-60{ }^{\circ} \mathrm{C}$ for $10 \mathrm{~min}$. To allow for catalytic conversion of L-arginine by arginase, lysates were incubated with $50 \mu \mathrm{l}$ of L-arginine $\left(0.5 \mathrm{M}\right.$; pH 9.7) at $37^{\circ} \mathrm{C}$ for $1 \mathrm{~h}$, before the reaction was stopped by addition of $400 \mu \mathrm{l}$ acid solution mixture $\left(1 \quad \mathrm{H}_{2} \mathrm{SO}_{4}: 3 \quad \mathrm{H}_{3} \mathrm{PO}_{4}: 7 \quad \mathrm{H}_{2} \mathrm{O}\right)$. For visualization, $25 \mu \mathrm{l}$ of $9 \% \alpha$-Isonitrosopropiophenone (in $100 \%$ ethanol) were added to the mixture and heated at $100{ }^{\circ} \mathrm{C}$ for $45 \mathrm{~min}$. Once the samples had been incubated in the dark for $10 \mathrm{~min}$ at RT, the urea concentration was determined by measuring the absorbance at $550 \mathrm{~nm}$ in a spectrophotometer. The rate of urea production was used as an index for arginase activity.

Ectonucleotidase expression on M1/M2-macrophages and on patient-derived TAMs was assessed with antiCD73-PE (BioLegend) or anti-CD39-PECy7 (Miltenyi) at 1:100. Specific Fluorescence Indices (SFI) were calculated for each surface marker by dividing the signal intensity obtained with the specific by the signal intensity measured with an irrelevant isotype-matched control antibody. All flow cytometry analyses were performed using a FACSCalibur flow cytometer (BD Biosciences, San Jose, USA).

CD39 and CD73 mRNA transcript levels were quantified from cDNA by semi-quantitative real time PCR (qRT-PCR) using the ABsolute Blue QPCR SYBR Green low Rox mix kit and the following primer pairs: CGGCTACCACATCCAAGGAA (frw) and GCTGGAA TTACCGCGGCT (rev) for 18S; GTAAGTGACCTTTA CAAGACCC (frw) and TGCTGGAATGGAAGAGTC ATC (rev) for CD39; GGCTCCTCTCAATCATGCCG (frw) and CAGAACATTTCATCCGTGTGT (rev) for CD73. Purity of the PCR products was assessed based on the dissociation curve. All samples were measured in duplicate and $\mathrm{Ct}$ (cycle threshold)-values were within $\leq 0.5$ cycles. mRNA expression was quantified relative to the expression 18S RNA which was used as control. 


\section{Adenosine production via CD39 and CD73}

Measurement of biologically active adenosine was performed as described before [7, 45]. Briefly, ADORA2Aoverexpressing HEK-293 cells were transiently transfected with the luciferase-encoding RIP1-CRE.luc ${ }^{+}$ cAMP-reporter plasmid [46]. Transfection efficiency was normalized via co-transfection of pRL-CMV (Promega, Madison, WI, USA). As adenosine binding to ADORA2A activates the adenylate cyclase, a corresponding firefly luciferase signal is obtained. Accordingly, a standard curve can be generated with a dynamic range from $20 \mathrm{nM}$ to $40 \mu \mathrm{M}$ adenosine. Specificity of the signal is controlled by use of HEK-293 cells without ADORA2A overexpression and by addition of the ADORA2A-specific inhibitor SCH58261 (Tocris, Bristol UK). M1- or M2macrophages generated as described above were coincubated at a 1:1 ratio with of RIP1-CRE.luc- and pRLCMV-transfected HEK-293 ADORA2A ${ }^{+}$cells for $4 \mathrm{~h}$. Cells were lysed with passive lysis buffer (Promega) and biophotonic signals were measured using a non-commercial dual luciferase assay (Dyer et al., 2000). Adenosine concentrations were calculated based on the co-determined standard curve. All measurements were performed in triplicates using an Orion II Microplate Luminometer (Berthold Detection Systems, Pforzheim, Germany). The specific inhibitors ARL67156 for CD39 $(100 \mu \mathrm{M})$ and APCP for CD73 $(100 \mu \mathrm{M})$ were added to confirm that the effects depend specifically on the respective ectonucleotidases.

\section{Proliferation of $\mathrm{CD}^{+} \mathrm{T}$ cells in co-culture with adenosine- generating cells}

CD4 $\mathrm{T}$ cell proliferation was measured as before [7]. $\mathrm{CD} 4{ }^{+}$ cells were isolated from PBMC using the $\mathrm{CD}^{+} \mathrm{T}$ cell isolation kit II (Miltenyi). Cells were then stained with $2.5 \mu \mathrm{M}$ 5-(and-6)-carboxyfluorescein diacetate succinimidyl ester (CFSE, Invitrogen, Karlsruhe, Germany). An agonistic antihuman CD3 antibody (clone UCHT-1, ImmunoTools) was immobilized on 96 well Maxisorp-plates (Nunc, Roskilde, Denmark) by overnight-incubation in PBS (antibody concentration: $1 \mu \mathrm{g} / \mathrm{ml}$ ). In coated wells, $\mathrm{T}$ cell stimulation could be induced by addition of soluble anti-human CD28 (clone 15E8, $1 \mu \mathrm{g} / \mathrm{ml}$, Immunotools). In each well, $2 \times 10^{6} \mathrm{~T}$ cells were co-incubated with $5 \times 10^{5} \mathrm{M} 2$ macrophages, in the absence or presence of the specific inhibitors ARL67156 for CD39 $(100 \mu \mathrm{M})$, APCP $(100 \mu \mathrm{M})$ for CD73 or solvent controls. As positive control, the metabolically stable adenosine receptor agonist adenosine- $5^{\prime}$-N-ethylcarboxamide (NECA, Tocris) was used at $10 \mu \mathrm{M}$. T cell proliferation was determined on a FACSCalibur flow cytometer (BD Biosciences) on day 7 (all [7]).

\section{Statistics}

For all experiments, significance was determined by Student's $t$-test. $p$-values $<0.05$ were considered to be significant. In R2 analysis, p-values were corrected for multiple testing. In flow cytometric assays at least 50,000 events were counted; two samples were considered to be significantly different $\left(^{*}\right)$ when they were separated by at least twice the sum of the standard deviations for the respective regions. A difference exceeding four times the sum of the respective standard deviations was considered as highly significant ${ }^{(* *)}$.

\section{Results \\ Expression of CD39 and CD73 in ovarian cancer tissue is associated with poor survival and correlates with transcripts expressed in myeloid cells}

To check for a possible correlation between CD39 and CD73 expression and survival in ovarian cancer patients, a web-based (http://kmplot.com/analysis/index.php?p= service\&cancer $=$ ovar) [42] Kaplan-Meier analysis including 347 patients with stage 3 and 4 (high-grade) serous ovarian cancer was performed. Using a combined classifier for both ectonucleotidases, CD39/CD73 ${ }^{\text {high }}$ tumors showed a hazard ratio of 1.32 (95 \% CI: $0.99-1.76$; $p=$ 0.062), thus indicating a trend towards worse survival for patients with tumors expressing CD39 and CD73 at significant levels (Fig. 1). Using the R2 database, gene expression data from 285 ovarian cancer tissues from the AOCS (Australian Ovarian Cancer Study) were screened for genes correlating with the presence of CD39 (ENTPD1(209473_at)) or, respectively, CD73 (Additional file 2: Table S1). Considering the strong correlation between both ectonucleotidases $\left(r=0.317, p=4.3 \times 10^{-8}\right)$, a considerable overlap could also be expected for genes which tend to be co-expressed with either CD39 or CD73. In this context, KEGG pathway analysis using the R2 pathway finder revealed for both CD39 $\left(p=1.5 \times 10^{-5}\right)$ and CD73 $\left(p=1.6 \times 10^{-3}\right)$ a highly significant correlation with antigen processing and presentation. 42 out of 57 genes linked to this pathway show correlation with CD39 $\left(p=1.5 \times 10^{5}\right)$. Likewise, 41 out of 57 pathway-associated genes also correlated with CD73 $\left(p=1.6 \times 10^{-3}\right)$ (see Additional file 3: Table S2). Pairwise correlation analyses subsequently indicated particularly strong positive correlations with MS4A7 (membrane-spanning 4-domains subfamily A member 7) $\left(p=2.5 \times 10^{-29}\right)$, myeloid differentiation protein-2, LY96 $\left(p=2.4 \times 10^{-34}\right)$, myeloid cell nuclear differentiation antigen MNDA $\left(p=1.1 \times 10^{-29}\right)$ and colony stimulating factor 2 receptor beta, CSF2RB $(p=$ $\left.2.4 \times 10^{-33}\right)$. Correlation between CD39 and CD68 was also highly significant $\left(p=2.4 \times 10^{-10}\right)$. Further pathways linked to CD39 expression include (among others), cytokine-cytokine receptor interaction $\left(p=7.9 \times 10^{-03}\right)$, cell adhesion $\left(p=4.4 \times 10^{-05}\right)$ and leukocyte_transendothelial_ migration $\left(p=8.3 \times 10^{-03}\right)$. For CD73 (NT5E), KEGG pathway analysis showed the strongest association with focal adhesion $\left(p=1.2 \times 10^{-05}\right)$, followed by cytokine_cytokine_ 


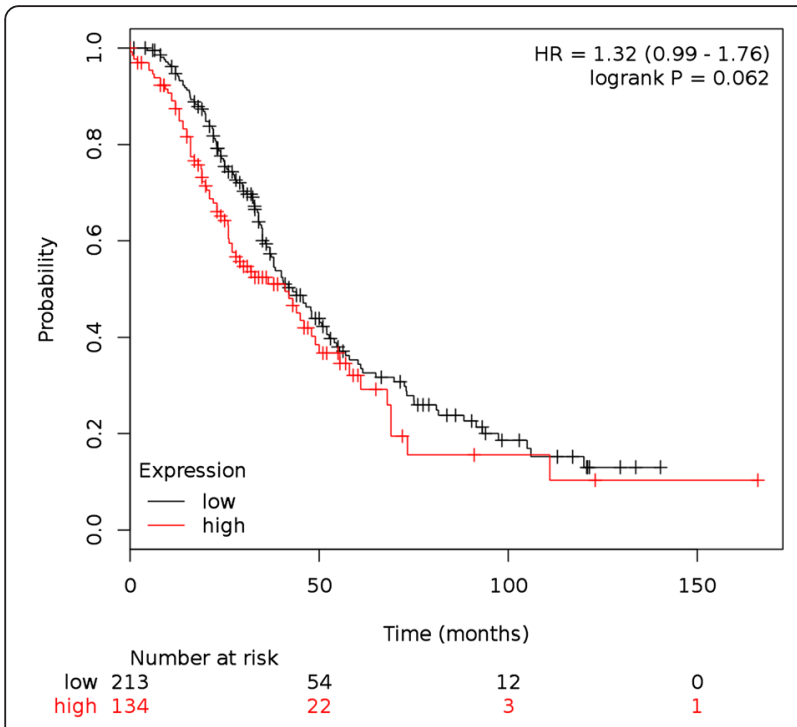

Fig. 1 Prognostic value of CD39 and CD73 expression in patients with high-grade serous OvCA. Using the ovarian cancer dataset available via the free online tool Kaplan-Meier plotter (http://kmplot. com/analysis/index.php?p=service\&cancer=ovar), expression of CD39 and CD73 was correlated with overall survival. All 347 patients with stage 3 and 4 serous OvCA were included, regardless of p53 status, CA125 levels, optimal/suboptimal debulking or chemotherapy. Based on a bioinformatically computed combined classifier comprising gene expression data for both CD39/ ENTPD1 (Affymetrix ID 228585) and CD73/NT5E (Affymetrix ID 203939), 134 patients (38.6 \%) were classified as CD39/CD73 ${ }^{\text {high }}$. Survival probabilities according to Kaplan-Meier were calculated together with $95 \%$ confidence intervals (Cls) and compared using two-sided log-rank tests

receptor_interaction $\left(p=4.3 \times 10^{-05}\right)$, ECM_receptor_interaction $\left(p=4.7 \times 10^{-04}\right)$, antigen processing and presentation $\left(p=1.6 \times 10^{-03}\right)$ and leukocyte transendothelial migration $\left(p=1.9 \times 10^{-03}\right)$ (see Additional file 2: Table S1). Patterns resembling specific diseases like tuberculosis, malaria or amoebiasis or processes like DNA replication or mismatch repair are not listed here. Pairwise correlations with MS4A7 $\left(p=3.6 \times 10^{-14}\right)$, LY96 $\left(p=9.1 \times 10^{-19}\right)$, MNDA $\left(p=5.6 \times 10^{-18}\right)$, CSF2RB $\left(p=6.9 \times 10^{-12}\right)$, and CD68 $\left(p=3,1 \times 10^{-6}\right)$ also showed correlation with CD73 expression. Moreover, phenotypical markers for myeloid cells (TAM or MDSC) [47] show a significant correlation with both CD39 and CD73 (see Additional file 4: Table S3). Possible explanations for these findings are either expression of ectonucleotidases on myeloid cells in the tumor tissue, or enhanced recruitment of myeloid cells when adenosine is generated.

\section{Expression of CD39 and CD73 by macrophages from ovarian cancer ascites and in ovarian cancer tissue}

$\mathrm{CD}_{14}{ }^{+}$cells were isolated via magnetic cell separation from fresh ascites samples of OvCA patients. These monocyte-derived cells which are likely to represent ex situ-TAMs were found to express both ectonucleotidases (CD39: 3/3 and CD73: 2/3; Fig. 2). In contrast, macrophages and monocytes from healthy donors as well as peritoneal macrophages from patients with benign disease showed negligible expression of both CD39 and CD73 (Fig. 2). With regard to solid ovarian cancer tissue, expression of CD39 and CD73 in ovarian cancer stroma was already shown in our previous study (Häusler et al., 2011). Aiming at a more precise cellular attribution of ectonucleotidase expression on tumor-associated myeloid cells, 10 OvCA cases, 1 healthy ovary and 1 placenta were investigated. Besides strong endothelial CD39 and CD73 stainings in both normal and neoplastic tissue regions on all OvCA samples, CD39 was clearly detectable on tumor-infiltrating immune cells in 7/10 samples with particularly strong stainings in two cases. Tumor cells, however, were only focally positive for CD39 with strong signals in $1 / 10$ and weak stainings in 9/10 OvCA samples (Fig. 3a; human tonsil serving as positive control as

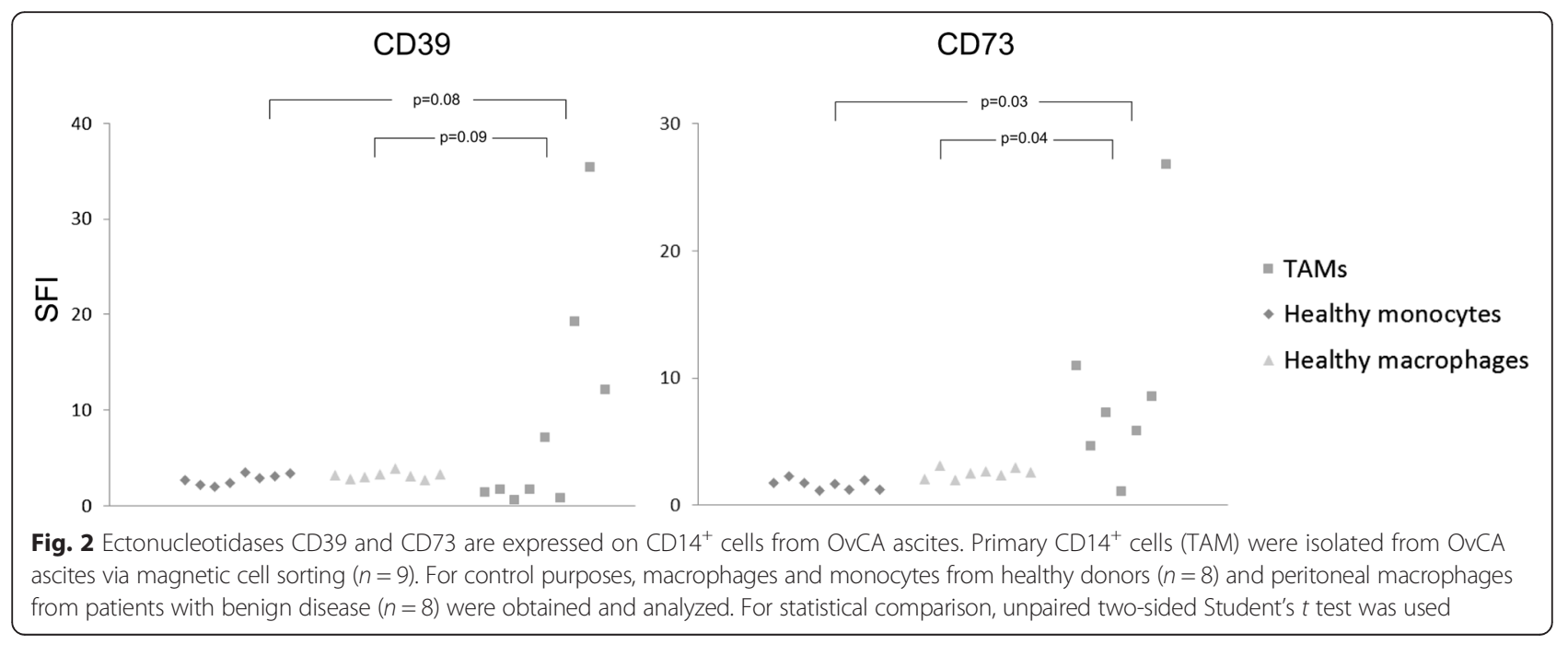




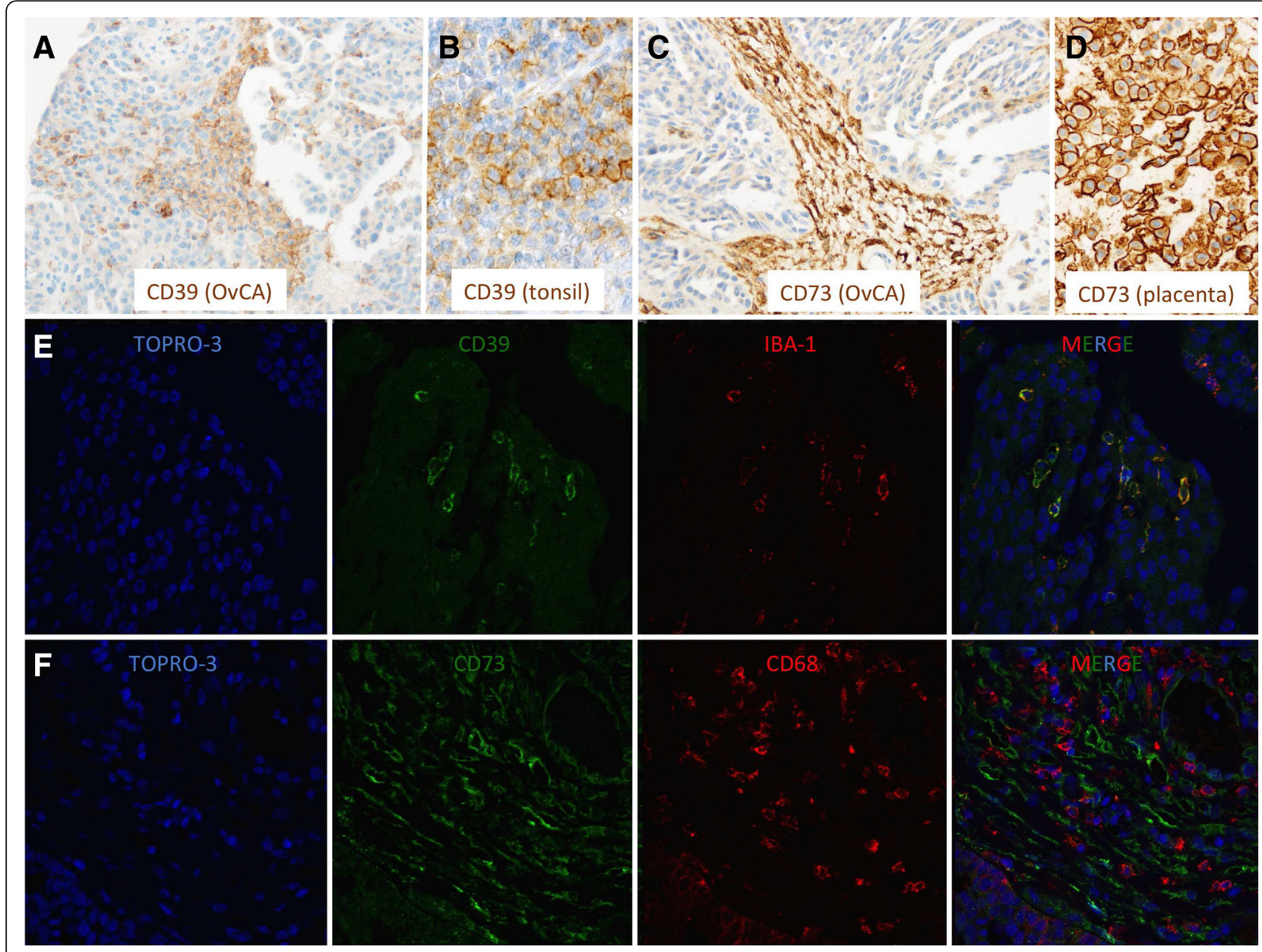

Fig. 3 CD39 is expressed on TAM while CD73 is strongly related to tumor stroma in OvCA. Representative immunohistochemical stainings for (a-b) CD39 and (c-d) CD73 showing that (a) CD39 is heterogeneously expressed on cells within the tumor parenchyma (b: tonsil serving as positive control) while (c) CD73 expression is largely restricted to the tumor stroma (d: placenta serving as positive control). (e-f) Immunfluorescent double stainings for (e) CD39 and IBA-1 as well as (f) CD73 and CD68 revealed a considerable co-expression of the macrophages markers with (e) CD39 but not with (f) CD73

shown in Fig. 3b). In the tumor stroma, CD39 showed a clear signal in $1 / 10$, but no more than weak focal stainings in 9/10 OvCA samples whereas CD73 was prominently expressed in all cases (Fig. 3c; human placenta serving as positive control as shown in Fig. 3d). On tumor cells, CD73 was highly expressed in $1 / 10$ cases, still prominently in 4/10 tissue samples, weak on $3 / 10$ sections and absent in 2/10 cases. Further CD73 expression was detected on tumor-infiltrating immune cells in 6/10 cases. To further determine a potential expression of CD39 and CD73 on myeloid cells, immunofluorescent double staining with myeloid markers were performed revealing a co-localization of CD39 with the macrophage marker IBA-1 (Fig. 3e). CD73, in contrast, was most prominently expressed on fibroblast-like tumor stromal cells without showing a co-localization with cells expression the myeloid marker CD68 (Fig. 3f). Having found that TAMs from ascites express CD39 and CD73 whereas myeloid cells in solid tumor tissue express no CD73 but moderate levels of CD39, ectonucleotidase levels on TAM or MDSC seems to be context-dependent and, likely, inducible. This, however, appears insufficient to explain the strong correlation between CD39, CD73 and myeloid markers found by gene expression analysis. Consequently, we wondered whether adenosine generated via ectonucleotidases on stromal or on tumor cells could attract myeloid cells towards the tumor tissue.

\section{OvCA cells increase the migration of myeloid precursor} cells by CD39- and CD73-dependent generation of adenosine

To analyze the migration behavior of human bloodborne myeloid cells, CD14 ${ }^{+}$monocytes were isolated from healthy volunteers and placed in the upper inserts of transwell plates. After $4 \mathrm{~h}$ of co-incubation with SKOV-3 or OAW-42 cells in the corresponding bottom 
compartments, migration of monocytes through the transwell-pores towards the OvCA cells was determined by flow cytometry. Unfortunately, the difficulties in measuring the easily degraded nucleoside adenosine did not allow concomitant determination of adenosine levels during the assay. However, based on our reporter gene assay conditions adenosine levels would typically be in the range from 1.1-1.7 $\mu \mathrm{M}$ for SK-OV-3 and 1.7-4.3 $\mu \mathrm{M}$ for OAW-42 cells. Under these conditions, pre-treatment of the tumor cells with the selective CD39- or CD73inhibitors ARL67156 or APCP did not affect their viability, but reduced monocyte migration by more than half, as compared to the solvent control. A similar effect was obtained by adding the A2A receptor inhibitor SCH58261 to the monocytes in the upper compartment. Conversely, when the metabolically stable adenosine receptor agonist NECA was applied, monocyte migration was increased by approximately two third (Fig. 4). Importantly, addition of NECA overruled the inhibition of CD39 and CD73 which indicates that the impaired migration was not due to direct effects of the inhibitors on the monocytes but rather to the reduced availability of adenosine (Fig. 4). While no evidence was obtained for enhanced chemokinesis in the presence of NECA, the co-culture setting does not allow to distinguish between direct chemotaxis towards adenosine or a more indirect effect by which adenosine might enhance cell migration towards another tumor-derived chemokine. Still, to screen whether adenosine might induce chemokine or chemokine receptor expression on monocytes, we performed an $\mathrm{RT}^{2}$ Profiler PCR array for human chemokines \& receptors followed by qRT-PCR for validation of individual candidate molecules (Additional file 1). This, however, showed only CCL28 and CXCL3/ GRO- $\gamma$ to be induced by NECA after $3 \mathrm{~h}$. As CCR10 which is the receptor for CCL28 could not be detected, CCL28 is most unlikely to mediate the observed migratory effect. CXCL3/GRO- $\gamma$ has, however, been described to affect monocyte differentiation and proliferation without altering their migration behavior [48, 49]. Thus, while an indirect or secondary effect on migration cannot be excluded, there is currently no evidence for this. Moreover, the experimental data show that irrespective of the underlying mechanism adenosine can attract monocytes towards tumor cells.

\section{M2-macrophages polarized by coculture with OvCA cells upregulate CD39 and CD73 to levels also observed in CD $14^{+}$cells from ovarian cancer ascites}

Immunosuppressive myeloid cells with a phenotype resembling tumor-associated macrophages (TAMs) can be induced by co-incubation of monocytes with OvCA cells [43]. Having found that OvCA cell-derived adenosine attracts monocytes towards the tumor cells, we wanted to confirm that these monocytes polarize to an M2-like phenotype which is characteristic for immunosuppressive TAM. Therefore, mature macrophages from healthy donors were co-incubated with OAW-42 cells in a transwell setting where macrophage migration to the
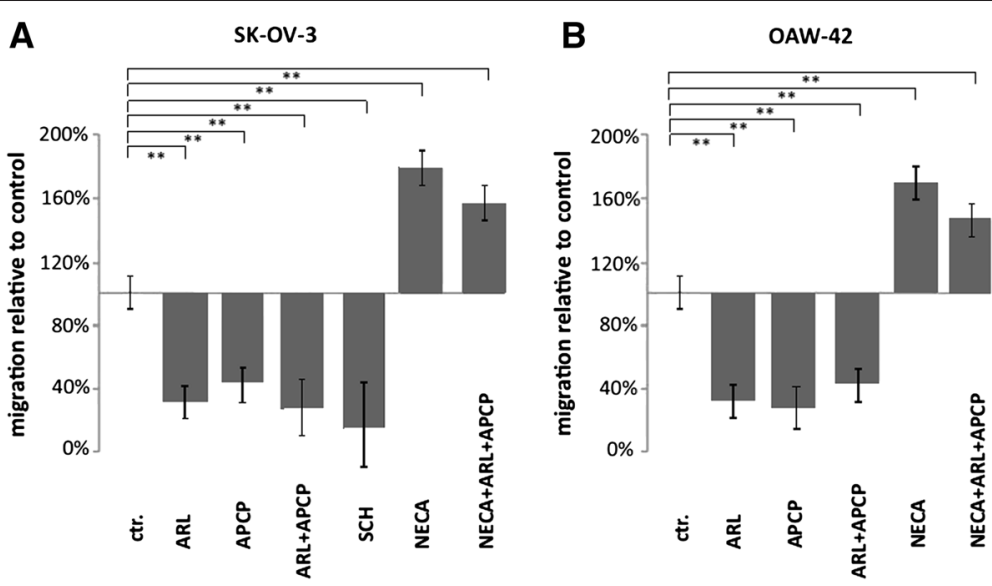

Fig. 4 CD39 and CD73 activity on OvCA cells promote monocyte migration in transwell chambers. Primary human monocytes were placed in the upper inserts of transwell plates while SK-OV-3 (a) or OAW-42 (b) OvCA cells were seeded in the respective bottom compartments. To explore a potential influence of ectonucleotidases, CD39 activity in tumor cells was inhibited by $100 \mu$ M ARL67156 whereas CD73 was inhibited with $100 \mu \mathrm{M}$ a, $\beta$-methyleneadenosine-5'-diphosphate (APCP). Equal amounts of solvent (DMSO) were added to the otherwise untreated controls. To exclude unwanted effects of the inhibitors on migrating monocytes, ovarian cancer cells were pre-incubated with the inhibitors for 30 min before being washed with PBS. To assess the effect of adenosine on monocyte migration directly, positive controls with the metabolically stable adenosine receptor agonist adenosine- $5^{\prime}-\mathrm{N}$-ethylcarboxamide (NECA) (used at $100 \mathrm{nM}$ ) were also included, both in the absence and in the presence of APCP and ARL67156 ( $n=3,{ }^{*}$ indicates $p<0.05,{ }^{* *}$ denotes $p<0.01$, as assessed by unpaired Student's $t$-test). As additional control, A2A receptor signalling was blocked during the assay by SCH58261 (in a). Under all conditions, migration of monocytes through the $8 \mu \mathrm{m}$ wide and $10 \mu \mathrm{m}$ thick pores was analyzed after $4 \mathrm{~h}$ by staining transmigrated cells for CD11c followed by flow cytometric analysis. Tumor cells from the bottom compartment were identified by co-staining for EpCAM expression 
lower chamber was precluded by the narrow porediameter of the transwell membrane. After $48 \mathrm{~h}$ of coculture, macrophages were analysed by intracellular flow cytometry for expression of IL-10 and IL-12. As opposed to M1-polarized macrophages that had been generated from monocytes in the presence of IFN- $\gamma$ and LPS, cocultured macrophages displayed high levels IL-10 and low levels of IL-12 confirming their M2-polarization (Fig. 5a).

High arginase activity is also related to a macrophage phenotype promoting tumor growth [50]. Consequently, co-cultured macrophages were further characterized using a colorimetric assay for arginase activity. This confirmed a higher enzymatic activity in the M2 polarized macrophages as well as in TAMs isolated from fresh ascites of OvCA patients (Fig. 5b).

Similar to recent reports on murine TAMs [39-41], human macrophages which had been co-cultured in vitro with ovarian cancer cells (OAW-42) also showed high expression of CD39 and CD73, both on mRNA (Fig. 5c) and on protein level (Fig. 5d). Acquisition of this phenotype was found to be independent of signaling via the A2A adenosine receptor since induction of CD39, CD73 and IL-10 also occurred when SCH58261 was present in the co-culture (Fig. 5e). In M1 macrophages, however, CD39 and CD73 surface levels were much lower (compare Fig. 5a). As this resembled the in vivo situation observed on TAMs from OvCA ascites shown in Fig. 2, we decided to further explore the functional consequences of ectonucleotidase expression on TAM-like M2 macrophages ("in vitro TAMs").

\section{Increased CD39 and CD73 expression on in vitro generated TAM-like M2 macrophages translates into higher levels of biologically active adenosine}

To investigate whether the high ectonucleotidase expression on M2 macrophages results in increased levels of biologically active adenosine, a luciferase-based adenosine reporter assay was performed as previously described [45]. In line with the observed expression of adenosinegenerating enzymes, pro-inflammatory M1-polarized macrophages produced only low amounts of adenosine $(0.27 \mu \mathrm{M} \pm 0.18 \mu \mathrm{M})$ whereas the TAM-like or M2polarized macrophages generated significantly higher levels of the immunosuppressive nucleoside (on average 3.8 $\mu \mathrm{M}$, range: 1.6-5.4 $\mu \mathrm{M}$ ) (Fig. 3). In the presence of specific inhibitors for CD39 (ARL 67156) and CD73 (APCP), adenosine production was almost abrogated (Fig. 6).

In vitro polarized $\mathrm{M} 2$ macrophages suppress $\mathrm{CD}^{+} \mathrm{T}$ cell proliferation via adenosine production

To test the functional relevance of increased adenosine generation by $\mathrm{M} 2$ macrophages, their effect on $\mathrm{CD}^{+} \mathrm{T}$ cell proliferation was investigated in coculture experiments with $\mathrm{CD}^{+} \mathrm{T}$ cells which had been stimulated with agonistic antibodies to $\mathrm{CD} 3$ and $\mathrm{CD} 28$. In this setting, TAM-like M2 macrophages decreased CD4 ${ }^{+} \mathrm{T}$ cell proliferation by $>50 \%$ (52\% on average, range: $47-$ $56 \%$ ) when compared to M1 macrophages (a representative example is shown in Fig. 7a, pooled data from 3 independent experiments are displayed in Fig. 7b). To specifically block ectonucleotidase activity on M2 macrophages, ARL67156, APCP, or both were added. Compared to solvent controls, $\mathrm{CD}^{+} \mathrm{T}$ cell proliferation was increased about 3.5-fold [range: 3.1 - 3.8-fold] by blockade of CD39 with ARL67156. Inhibition of CD73 by APCP enhanced $\mathrm{T}$ cell proliferation by a factor of 2.7 [range: 2.4 - 3.0] (Fig. 7). Considering that both APCP and ARL67156 already abrogated adenosine production when used on their own (compare Fig. 6), no further improvement could be expected by their combination. Instead, a somewhat diminished effect was observed which may be due to slight toxic effects caused by the simultaneous use of both inhibitors (Fig. 7).

\section{Discussion}

In hypoxic tissues or after chemotherapeutic treatments, dying tumor cells are abundant. ATP released by these cells $[7,51-53]$ constitutes an immunological danger signal which can activate dendritic cells [35]. ATP can, however, be rapidly converted to adenosine which is known to suppress $\mathrm{CD}^{+} \mathrm{T}, \mathrm{CD} 8^{+} \mathrm{T}$ and NK cells $[7,14,54]$. In fact, we and others have already shown that ovarian cancer cells and tissues can express high levels of the ectonucleotidases CD39 and CD73 which enzymatically convert free extracellular ATP to adenosine. CD39 (which catalyzes the degradation of pro-inflammatory ATP to AMP) even showed a highly tumor-specific expression pattern in the female reproductive tract. CD73 (which generates adenosine from AMP) was likewise significantly overexpressed in tumor tissues [7]. Moreover, strategies directed at the inhibition of CD73 (and thus at the prevention of adenosine generation), have shown impressive results in animal models of breast and ovarian cancer $[8,10,55]$. Nevertheless, both positive and negative correlations between CD39 and CD73 expression and outcome have been described [56-59]. The desirable analysis whether local adenosine levels affect prognosis is unfortunately precluded by the short half-life of adenosine. Gene expression analysis, however, suggests that combined overexpression of CD39 and CD73 is associated with a trend towards poor survival (Fig. 1, $p=0.062, n=347$ patients).

A clear correlation has, in contrast, been found for infiltration of ovarian tumors with myeloid cells and rapid tumor progression, metastasis and poor prognosis [24-26]. As human studies are confined to readily available biological materials, we used monocytes as 

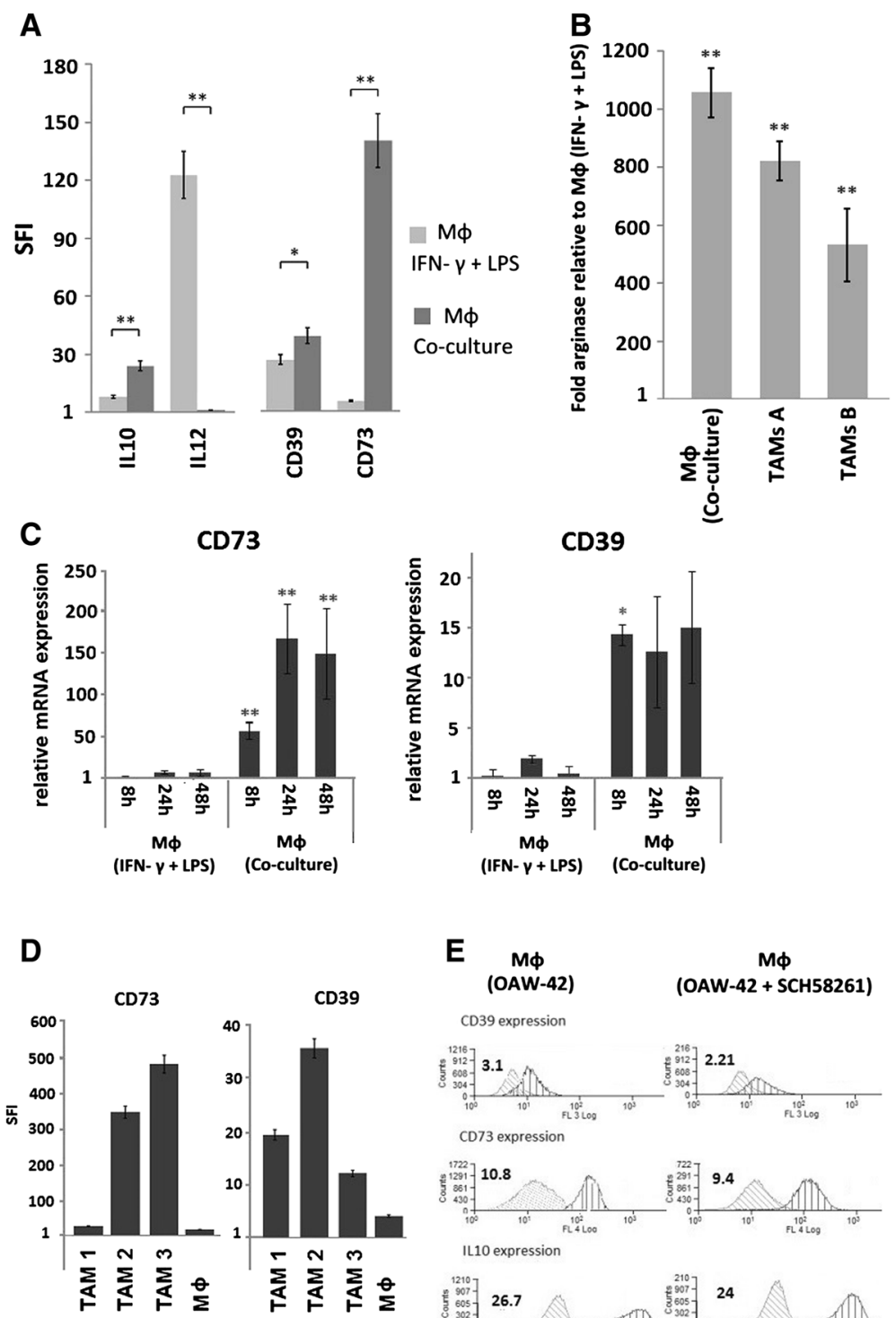

E $M \phi$ (OAW-42) CD39 expression

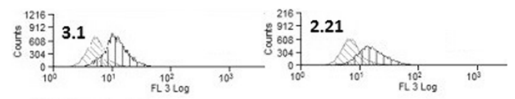

CD73 expression

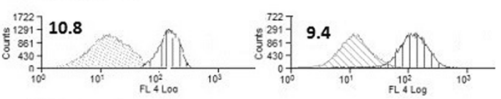

IL10 expression

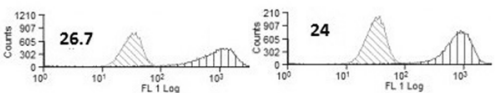

Fig. 5 In vitro induced TAM-like macrophages show M2-polarization, arginase activity and ectonucleotidase expression. Peripheral blood monocytes were obtained from healthy volunteers by gradient centrifugation and subsequent adherence enrichment. Monocytes were then matured in Lumox dishes for 9 days to obtain mature macrophages (MФ). Macrophage polarization was achieved either with IFN- $\gamma$ [1 $\mu \mathrm{g} / \mathrm{ml}$ ] and

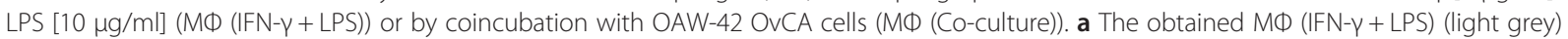
and MФ (Co-culture) (dark grey) were analyzed by FACS for intracellular IL-10 and IL-12 levels. To obtain specific fluorescence intensity (SFI) values, the median fluorescence values obtained with fluorochrome-conjugated specific antibodies were divided by the median fluorescence values obtained with identically labeled irrelevant isotype-matched control antibodies $\left(n=3,{ }^{*}\right.$ for $p<0.05,{ }^{* *}$ for $\left.p<0.01\right)$. b CD14 ${ }^{+}$cells (TAM) were isolated from malignant tumor tissue. In addition, mature macrophages from a healthy donor were polarized as in $\mathbf{a}$. To determine arginase activity by MФ (IFN- $-\gamma+$ LPS) and MФ (Co-culture) as well as by TAM, arginine conversion was assessed by measuring the resulting urea in a colorimetric assay. Significance levels were determined by two-sided, unpaired Student's $t$-test. $p$-values $<0.01$ were considered as highly significant $\left.{ }^{(*}\right)$. c Macrophages were prepared and polarized as in a. 8 h, $24 \mathrm{~h}$ and $48 \mathrm{~h}$ after the polarizing conditions had been applied, RNA was isolated, reverse-transcribed to CDNA and analyzed for CD39 and CD73 transcript levels using SybrGreen-based RT-PCR. 18S rRNA content was determined for normalization and relative CD39 and CD73 mRNA levels were calculated by the $\Delta \Delta C_{t}$ method using non-polarized macrophages as reference. $\mathbf{d}$ Using $M \Phi(I F N-\gamma+$ LPS) and MФ (Co-culture) as in c, CD39 and CD73 surface expression was assessed by flow cytometry. e Macrophages were polarized with OAW-42 cells for $24 \mathrm{~h}$ in the presence or absence of the A2A adenosine receptor inhibitor SCH58261 before IL-10, CD39 and CD73 expression were analysed by flow cytometry. Comparable data for primary TAMs isolated from OvCA ascites are shown in Fig. 2 


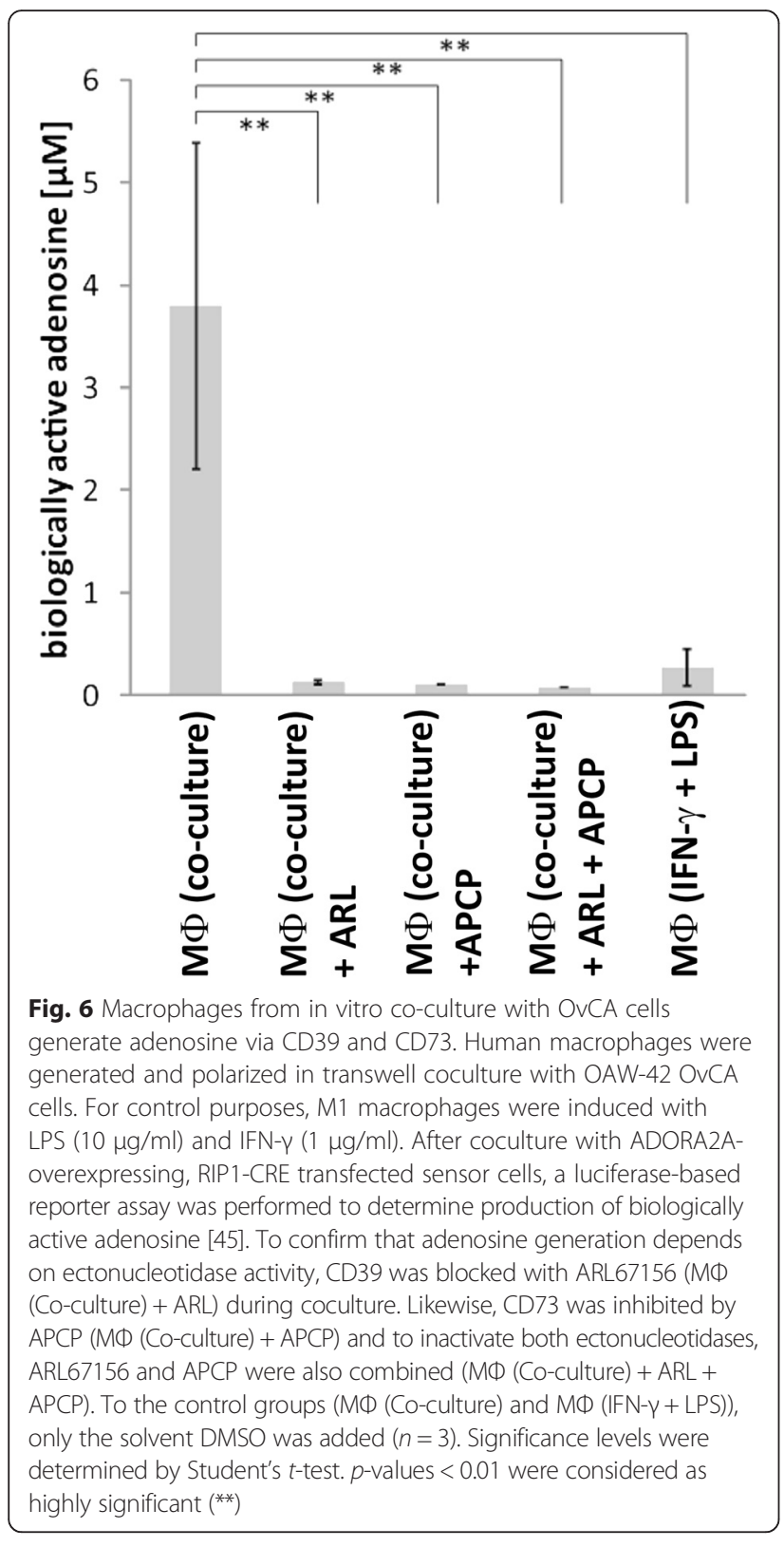

easily available human myeloid cells and co-cultured them with ovarian cancer cells, thereby mimicking the maturation and M2 differentiation of myeloid cells in the tumor microenvironment [43]. CD14 ${ }^{+}$cells derived from ascites (Fig. 2) were used ex vivo to corroborate the in vitro findings. Based on these cellular model systems, we could show that OvCA-derived adenosine exerts direct or indirect chemotactic effects on human monocytes (Fig. 4) and is thus likely to attract myeloid precursor cells towards the tumor tissue. Moreover, in a microenvironment that is shaped by OvCA cells, human monocytes differentiate into M2-polarized macrophages or TAM (Fig. 5) which express IL-10 rather than IL-12 and show arginase activity. While signalling via the A2A adenosine receptor is not required for M2 polarization, M2 macrophages express significant levels of the adenosine-generating ectonucleotidases CD39 and CD73, both on mRNA and protein level (Fig. 6). This is in line with recent reports on CD73 expression by murine MDSC which were also shown to suppress immune responses in an adenosinedependent way $[19,39,40]$. Moreover, $\mathrm{CD} 14^{+}$cells isolated from OvCA ascites also showed much higher levels of CD39 and, in particular, CD73 than macrophages from non-malignant control ascites (Fig. 2). Interestingly, similar findings were also reported in a most recent publication describing an IL-27 dependent induction of CD39 on macrophages in ovarian cancer patients [60]. Using a reporter gene assay developed in our laboratory [45], we could then confirm that the amount of biologically active adenosine generated by M2 macrophages was similar to the levels produced by OvCA cells [7], i.e., in the low micromolar range (Fig. 4) and thus 30-60-fold higher than the already immunosuppressive levels from $\mathrm{T}_{\text {reg }}$ [45]. Consequently, co-culture experiments also confirmed that M2 macrophages exert strong anti-proliferative effects on activated $\mathrm{CD} 4^{+} \mathrm{T}$ cells. Importantly, $\mathrm{T}$ cell proliferation was largely restored when CD39 or CD73 were blocked by ARL67156 or APCP, respectively, thereby confirming the pivotal role of adenosine in the observed T cell inhibition (Fig. 7).

While these data show that ectonucleotidase expression by myeloid cells may be functionally relevant, an attribution to either MDSC or TAM was not attempted in our study. As monocytic MDSC which are predominant in tumor tissues $[28,29]$ tend to rapidly differentiate into TAM [61], discrimination between these cell types is difficult and gradual. Polymorphonuclear MDSC, in contrast, do not develop into TAM and should thus be seen as different cell population [62]. Using common myeloid markers, immunohistochemical analysis of solid ovarian tumor tissue failed to show a co-localization of CD73 with CD68 (Fig. 3f). CD39, in contrast, could be co-stained with the macrophage marker IBA-1 (Fig. 3e). While the limited sensitivity of immunohistochemical analysis may also contribute to the apparent lack of CD73 on TAM or MDSC in solid ovarian cancer tissue, expression of ectonucleotidases on myeloid cells may also be context-dependent and could require e.g., inflammatory stimuli as found in ascites or under in vitro conditions. Still, both CD39 and CD73 were detected on both tumor and stromal cells in ovarian cancer tissue and prominent expression was found on endothelial cells from the tumor vasculature. Infiltrating immune cells may thus be already exposed to adenosine during transmigration into the tissue. Further, recruitment of macrophage precursor cells via adenosine-dependent chemotaxis may be particularly efficient when adenosine is generated at the tumor-vessel interface. The partial co-expression between CD39 and IBA- $1^{+}$cells is certainly insufficient to fully 

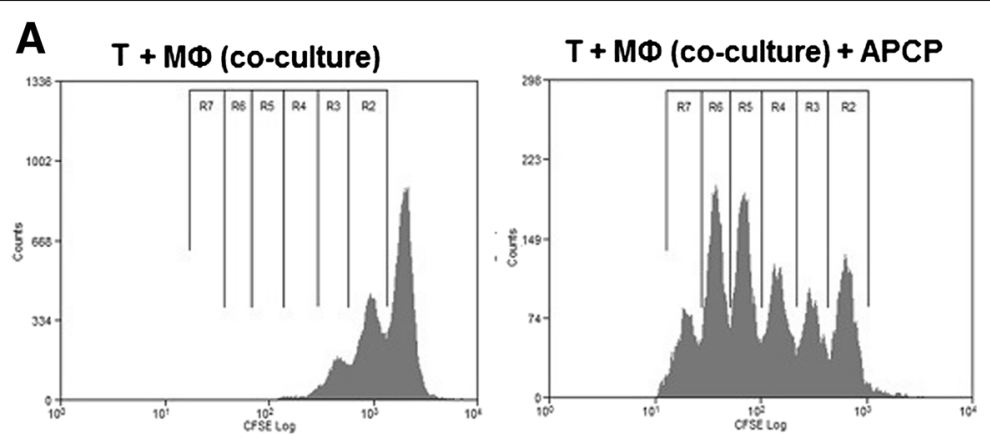

$T+M \Phi($ co culture) + ARL
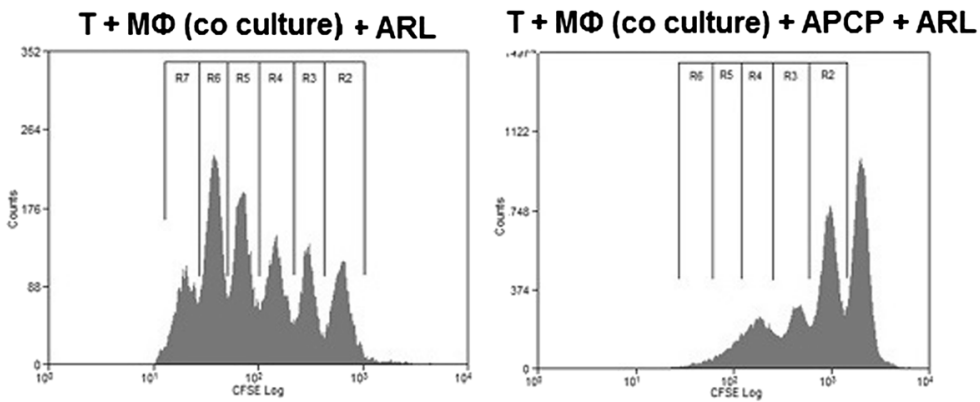

B

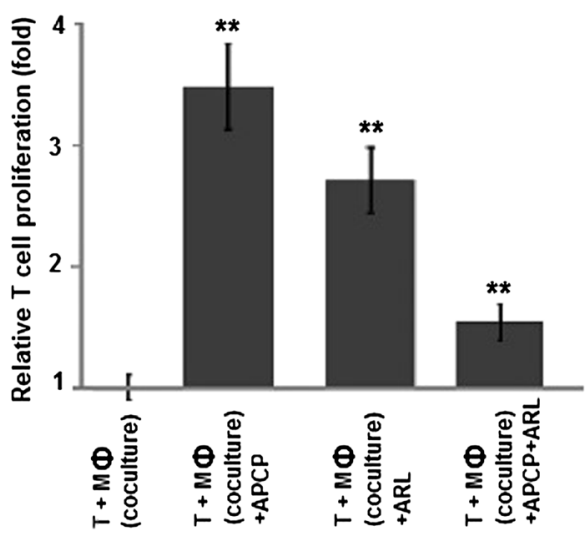

Fig. 7 "TAM-like" macrophages suppress CD4 ${ }^{+} T$ cell proliferation via a CD39 and CD73-dependent mechanism. Polarized macrophages were generated in co-culture with OAW-42 OvCA cells whereas M1 macrophages were induced by treatment with LPS and IFN- $\gamma$. CD4 ${ }^{+}$T cells were isolated from healthy volunteers and stained with CFSE before activation with plate-bound anti-CD3 and soluble anti-CD28 antibodies. Activated $\mathrm{CFSE}^{+} \mathrm{CD}^{+} \mathrm{T}$ cells were then co-incubated with M2 macrophages in the absence $(T+\mathrm{M} \Phi$ (Co-culture)) or presence of CD39 or CD73-inhibitors ARL67156 ( $T+M \Phi$ (Co-culture) + ARL) or, respectively, APCP ( + + MФ (Co-culture) + APCP), or a combination of both ( $T+M \Phi(C o-C u l t u r e)+A R L+$ APCP). T cell proliferation was determined by flow cytometry via CFSE dilution, as described previously [7] $\left(n=3,{ }^{* *}\right.$ indicates $p<0.01$ as assessed by unpaired, two-sided Student's $t$-test). While a representative histogram is shown in $\mathbf{a}$, mean values from three independent experiments are depicted in (b)

account for the strong correlation between macrophagespecific genes and ectonucleotidase expression (Additional file 2: Table S1 and Additional file 3: Table S2) or for the highly significant association between CD39, CD73 and the KEGG data set for antigen processing and presentation (Additional file 4: Table S3). An additional adenosinedependent recruitment of myeloid cells to the tumor microenvironment may therefore also have contributed to the strong correlations found by unbiased transcriptome analyses from 285 ovarian cancer tissues.
As this study aimed at establishing a link between adenosine and myeloid cells in the tumor microenvironment, the mechanism responsible for the adenosinedependent recruitment of monocytes towards tumor cells was not investigated in detail. In the literature, diverse effects of adenosine on cell migration have already been reported: While ATP enhances the non-directional motility of monocytes [63], degradation of ATP to adenosine by CD39 was found to promote the chemotactic migration of myeloid cells in a modified Boyden chamber 
assay. Consequently, chemotaxis of CD39-deficient monocytes/macrophages was impaired [64]. As this effect could also be rescued by addition of NECA, it is fully consistent with our observations made with ARL67156 and NECA. Similar findings on adenosine and cell migration were reported for neutrophils and initially attributed to the involvement of the A2 adenosine receptor [65]. Later, an addtitional and possibly stronger contribution from the A1 adenosine receptor was described [66]. In a more complex system involving a pericellular matrix and smooth muscle cells, adenosine also promoted the migration of monocytes/macrophages and their trapping in the interstitial matrix. This, however, was ascribed to an indirect effect caused by hyaluronic acid synthase being induced via the $\mathrm{A} 2 \mathrm{~B}, \mathrm{~A} 2 \mathrm{~A}$ and $\mathrm{A} 3$ adenosine receptors, with different kinetics for each receptor [67]. Without agreeing on a single mode-of-action, various reports have thus already described direct and indirect pro-migratory effects of adenosine on monocyte. Consistent with its overall antiinflammatory effect, adenosine may, in contrast, also reduce the migration of pro-inflammatory cell types [68]. This may also apply to activated monocytes and microglia which were reported to migrate less in response to activation of the A3 adenosine receptor [69]. Adenosine was further found to slow the migration of dendritic cells [70] and to inhibit transendothelial migration of conventional $\mathrm{T}$ cells via an indirect monocyte-dependent mechanism [71]. While these divergent effects may be due to cell type and activation state-dependent expression patterns of adenosine receptors $\mathrm{A} 1, \mathrm{~A} 2 \mathrm{~A}, \mathrm{~A} 2 \mathrm{~B}$ and $\mathrm{A} 3$, the analysis of receptor distribution is hampered by the lack of suitable antibodies against the individual receptor subtypes. Still, it appears clear that adenosine can affect cell migration via direct and indirect mechanisms involving different adenosine receptors depending on cell type, assay and kinetics.

\section{Conclusion}

Our findings that human monocytes are attracted by adenosine while M2 macrophages can contribute to local immunosuppression via adenosine generation suggest a self-amplifying mechanism: Similar to what has already been described in mice [40] and what needs to be further explored in vivo, tumor-derived adenosine might promote recruitment of further adenosine-generating cells towards the microenvironment in human cancer patients. Infiltration with MDSC or TAM would then be both a consequence and a further source of tumor-derived adenosine. This might further explain the very potent effects observed with anti-CD73 and anti-ADORA2A directed strategies in animal tumor models $[8,10,55]-$ and it could show a new strategy to interfere with MDSC, TAM and their tumor-promoting role in ovarian cancer. Importantly, the substances we used to specifically block CD39 and CD73 activity are already being tested in vivo for other diseases: APCP was found to be highly beneficial in a mouse melanoma model [72] whereas the CD39inhibitor ARL67156 has shown promise for the treatment of hepatic insulin resistance [73]. Thus, such inhibitors might also become available for the clinical treatment of malignant diseases. Based on previous findings and on the data outlined in this manuscript, there certainly is a strong rationale for a potential use of ectonucleotidase inhibitors in the immunotherapeutic treatment of ovarian cancer.

\section{Additional files}

Additional file 1: $R T^{2}$ Profiler $P C R$ array for human chemokines \& receptors. (DOCX $184 \mathrm{~kb})$

Additional file 2: Table S1. KEGG pathway analysis using the R2 pathway finder. List of pathways significantly correlated with the expression of CD39 or CD73 and their respective p values. (DOCX $15 \mathrm{~kb}$ )

Additional file 3: Table S2. Analysis of the antigen processing and presentation pathway and gene-wise correlation with the expression of CD39 (ENTPD1) and CD73 (NT5E). Out of 57 genes linked to this pathway 42 genes show correlation with CD39 and 41 genes correlate with CD73. (DOCX $15 \mathrm{~kb}$ )

Additional file 4: Table S3. Gene expression correlation analysis. Correlation between CD39 (ENTPD-1) or CD73 (NT5E) and phenotypic markers on human myeloid cells. Gene expression data from 285 ovarian cancer tissues from the AOCS (Australian Ovarian Cancer Study) were screened for genes correlating with the presence of CD39 (ENTPD-1) or CD73 (NT5E). Pairwise correlation analyses indicated positive correlations between almost all phenotypical markers described for MDSC (Talmadge and Gabrilovich, 2013) and the ectoenzymes CD73 and CD39. (DOCX 14 kb)

\section{Abbreviations}

(R-)PE, R-phycoerithrin; ADORA2A, adenosine receptor 2A; APCP, a, $\beta$-methyleneadenosine-5'-diphosphate; ARL67156, 6-N,N-Diethyl-D- $\beta, \gamma$-dibromomethyleneATP trisodium salt; CCL, CC-chemokine ligand; CFSE, carboxyfluorescein diacetate succinimidyl ester; $\mathrm{Cl}$, confidence interval; $\mathrm{CRE}, \mathrm{CAMP}$ responsive element; CXCL, CXC-chemokine ligand; DAB, diaminobenzidine; DMSO, dimethyl sulfoxide; ENTPD1, ectonucleoside triphosphate diphosphohydrolase 1; FITC, Fluorescein isothiocyanate; GRO- $\gamma$, growth regulated oncogene gamma; hrp, horseradish peroxidase; IBA1, ionized calcium-binding adapter molecule 1 (also known as Allograft inflammatory factor 1 (AIF-1)); IDO, indoleamine-2,3dioxygenase; KEGG, Kyoto encyclopedia of genes and genomes; LPS, lipopolysaccharide; Luc, firefly (photinus pyralis) luciferase; MDSC, myeloidderived suppressor cells; NECA, adenosine-5'-N-ethylcarboxamide; NK, natural killer (cells); OvCA, ovarian cancer; PBMC, peripheral blood mononuclear cells; $\mathrm{RIP1}$, rat insulin 1 gene promoter; $\mathrm{RL}$, renilla reniformis luciferase; $\mathrm{ROS}$, reactive oxygen species; SCH58261, 5-Amino-7-(2-phenylethyl)-2-(2-furyl)-pyrazolo(4,3-e)1,2,4-triazolo(1,5-c)pyrimidine; TAM, tumor associated macrophages; $T_{\text {reg, }}$ regulatory $T$ cells

\section{Acknowledgement}

We thank Evi Horn and Birgitt Fischer for excellent technical assistance.

\section{Funding}

This work was supported by a grant (Z3_10) awarded by the Interdisciplinary Center for Clinical Research (IZKF) Würzburg, Josef-Schneider-Stasse 4, 97080 Würzburg to Sebastian Häusler.

\section{Availability of data and material}

The datasets analysed during the current study are available from the corresponding author upon reasonable request.

\section{Authors' contributions}

The study was designed and guided by JW and SFMH, with support from JD (Dietl). Experiments were performed by IMdB, CP, LS, SFMH and RS, MBL and MM planned and supervised individual experiments. IMdB, CP, LS, RS, JD 
(Diessner), MBL, MM, JW and SFMH analyzed experimental data. RS, JD (Diessner), AW, JD (Dietl) and SFMH contributed clinical data and samples, $I M d B, M B L, M M, J W$ and SFMH were involved in writing the manuscript, $C P$, LS, RS, JD (Diessner) and JD (Dietl) critically reviewed the manuscript. All authors read and approved the final manuscript. None of the authors is aware of any open question relating to the accuracy or integrity of the work.

\section{Authors' information}

Not applicable.

\section{Competing interests}

None of the authors is aware of any potential conflict of interest related to this work.

\section{Consent for publication}

Not applicable.

\section{Ethics approval and consent to participate}

The study was completely non-interventional. Tumor tissue, ascites and immune cells (from leukocyte reduction chambers from the local blood bank) were obtained for medical reasons and would otherwise have been discarded. All donors had agreed that such material may be used for non-commercial research if fully anonymized. As no individual patient-related data were assessed during these investigations, no study-specific informed consent was required for the use of biological samples in this study. This proceeding has been discussed with the ethical committee at the University of Würzburg Medical School, Institute for Pharmacology and Toxicology, Versbacher Strasse 9, 97078 Würzburg, Germany.

Investigation of anonymized biomaterials obtained for medical reasons was approved by the local ethics committee. Upon admission to the hospital, patients signed a declaration of consent for such use.

\section{Author details}

${ }^{1}$ Department of Obstetrics and Gynaecology, University of Würzburg, School of Medicine, Josef-Schneider-Strasse 4, 97080 Würzburg, Germany. ${ }^{2}$ Interdisciplinary Centre for Clinical Research, University of Würzburg, School of Medicine, Würzburg, Germany. ${ }^{3}$ German Cancer Consortium (DKTK), German Cancer Research Center (DKFZ), Heidelberg, Germany. ${ }^{4}$ Edinger Institute (Neurological Institute), Goethe University, Frankfurt, Germany. ${ }^{5}$ Institute of Virology and Immunobiology, University of Würzburg, Versbacherstrasse 7, 97078 Würzburg, Germany.

Received: 7 March 2016 Accepted: 25 July 2016

Published online: 16 August 2016

\section{References}

1. Wertel I, Nowicka A, Rogala E, Kotarski J. Peritoneal immune system in patients with advance epithelial ovarian cancer. Int Rev Immunol. 2011;30:87-101.

2. Zhang L, Conejo-Garcia JR, Katsaros D, Gimotty PA, Massobrio M, Regnani G, Makrigiannakis A, Gray H, Schlienger K, Liebman MN, et al. Intratumoral T cells, recurrence, and survival in epithelial ovarian cancer. N Engl J Med. 2003;348:203-13

3. Curiel TJ, Coukos G, Zou L, Alvarez X, Cheng P, Mottram P, Evdemon-Hogan $\mathrm{M}$, Conejo-Garcia JR, Zhang L, Burow M, et al. Specific recruitment of regulatory $T$ cells in ovarian carcinoma fosters immune privilege and predicts reduced survival. Nat Med. 2004;10:942-9.

4. Fridman WH, Galon J, Pages F, Tartour E, Sautes-Fridman C, Kroemer G. Prognostic and predictive impact of intra- and peritumoral immune infiltrates. Cancer Res. 2011;71:5601-5.

5. Hamanishi J, Mandai M, Abiko K, Matsumura N, Baba T, Yoshioka Y, Kosaka K, Konishi I. The comprehensive assessment of local immune status of ovarian cancer by the clustering of multiple immune factors. Clin Immunol. 2011;141:338-47.

6. Blay J, White TD, Hoskin DW. The extracellular fluid of solid carcinomas contains immunosuppressive concentrations of adenosine. Cancer Res. 1997:57:2602-5.

7. Häusler SF, Montalban del Barrio I, Strohschein J, Anoop Chandran P, Engel JB, Hönig A, Ossadnik M, Horn E, Fischer B, Krockenberger M, et al. Ectonucleotidases CD39 and CD73 on OvCA cells are potent adenosinegenerating enzymes responsible for adenosine receptor 2A-dependent suppression of T cell function and NK cell cytotoxicity. Cancer Immunol Immunother. 2011;60:1405-18.

8. Jin D, Fan J, Wang L, Thompson LF, Liu A, Daniel BJ, Shin T, Curiel TJ, Zhang B. CD73 on tumor cells impairs antitumor T-cell responses: a novel mechanism of tumor-induced immune suppression. Cancer Res. 2010;70:2245-55.

9. Ohta A, Gorelik E, Prasad SJ, Ronchese F, Lukashev D, Wong MK, Huang X, Caldwell S, Liu K, Smith P, et al. A2A adenosine receptor protects tumors from antitumor T cells. Proc Natl Acad Sci U S A. 2006;103:13132-7.

10. Stagg J, Beavis PA, Divisekera U, Liu MC, Moller A, Darcy PK, Smyth MJ. CD73-deficient mice are resistant to carcinogenesis. Cancer Res. 2012;72:2190-6.

11. Antonioli L, Fornai M, Colucci R, Ghisu N, Tuccori M, Del Tacca M, Blandizzi C. Regulation of enteric functions by adenosine: pathophysiological and pharmacological implications. Pharmacol Ther. 2008;120:233-53.

12. Hasko G, Linden J, Cronstein B, Pacher P. Adenosine receptors: therapeutic aspects for inflammatory and immune diseases. Nat Rev Drug Discov. 2008; 7:759-70.

13. Csoka B, Himer L, Selmeczy Z, Vizi ES, Pacher P, Ledent C, Deitch EA, Spolarics Z, Nemeth ZH, Hasko G. Adenosine A2A receptor activation inhibits T helper 1 and T helper 2 cell development and effector function. FASEB J. 2008:22:3491-9.

14. Hasko G, Cronstein BN. Adenosine: an endogenous regulator of innate immunity. Trends Immunol. 2004;25:33-9.

15. Himer L, Csoka B, Selmeczy Z, Koscso B, Pocza T, Pacher P, Nemeth ZH, Deitch EA, Vizi ES, Cronstein BN, Hasko G. Adenosine A2A receptor activation protects CD4+ T lymphocytes against activation-induced cell death. FASEB J. 2010;24:2631-40

16. Longhi MS, Robson SC, Bernstein SH, Serra S, Deaglio S. Biological functions of ecto-enzymes in regulating extracellular adenosine levels in neoplastic and inflammatory disease states. J Mol Med (Berl). 2013;91:165-72.

17. Chan ES, Cronstein BN. Adenosine in fibrosis. Mod Rheumatol. 2010;20:114-22.

18. Karmouty-Quintana H, Xia Y, Blackburn MR. Adenosine signaling during acute and chronic disease states. J Mol Med (Berl). 2013;91:173-81.

19. Beavis PA, Stagg J, Darcy PK, Smyth MJ. CD73: a potent suppressor of antitumor immune responses. Trends Immunol. 2012;33:231-7.

20. Deaglio S, Dwyer KM, Gao W, Friedman D, Usheva A, Erat A, Chen JF, Enjyoji $K$, Linden J, Oukka M, et al. Adenosine generation catalyzed by CD39 and CD73 expressed on regulatory $T$ cells mediates immune suppression. J Exp Med. 2007;204:1257-65.

21. Krysko DV, Garg AD, Kaczmarek A, Krysko O, Agostinis P, Vandenabeele P. Immunogenic cell death and DAMPs in cancer therapy. Nat Rev Cancer. 2012;12:860-75

22. Resta R, Yamashita Y, Thompson LF. Ecto-enzyme and signaling functions oflymphocyte CD73. Immunol Rev. 1998;161:95-109.

23. Condamine T, Ramachandran I, Youn Jl, Gabrilovich DI. Regulation of tumor metastasis by myeloid-derived suppressor cells. Annu Rev Med. 2015;66:97-110

24. Neyen C, Pluddemann A, Mukhopadhyay S, Maniati E, Bossard M, Gordon S, Hagemann T. Macrophage scavenger receptor a promotes tumor progression in murine models of ovarian and pancreatic cancer. J Immunol. 2013;190:3798-805.

25. Qian BZ, Pollard JW. Macrophage diversity enhances tumor progression and metastasis. Cell. 2010;141:39-51.

26. Reinartz S, Schumann T, Finkernagel F, Wortmann A, Jansen JM, Meissner W Krause M, Schworer AM, Wagner U, Muller-Brusselbach S, Muller R. Mixedpolarization phenotype of ascites-associated macrophages in human ovarian carcinoma: correlation of CD163 expression, cytokine levels and early relapse. Int J Cancer. 2014;134:32-42.

27. Sica A, Bronte V. Altered macrophage differentiation and immune dysfunction in tumor development. J Clin Invest. 2007;117:1155-66.

28. Kumar V, Cheng P, Condamine T, Mony S, Languino LR, McCaffrey JC, Hockstein N, Guarino M, Masters G, Penman E, et al. CD45 phosphatase inhibits STAT3 transcription factor activity in myeloid cells and promotes tumor-associated macrophage differentiation. Immunity. 2016;44:303-15.

29. Kumar V, Patel S, Tcyganov E, Gabrilovich DI. The nature of myeloid-derived suppressor cells in the tumor microenvironment. Trends Immunol. 2016;37: 208-220.

30. Tang $X$, Mo C, Wang Y, Wei D, Xiao H. Anti-tumour strategies aiming to target tumour-associated macrophages. Immunology. 2013;138:93-104. 
31. Lewis C, Murdoch C. Macrophage responses to hypoxia: implications for tumor progression and anti-cancer therapies. Am J Pathol. 2005;167:627-35.

32. Pollard JW. Tumour-educated macrophages promote tumour progression and metastasis. Nat Rev Cancer. 2004:4:71-8.

33. Kawamura K, Komohara Y, Takaishi K, Katabuchi H, Takeya M. Detection of M2 macrophages and colony-stimulating factor 1 expression in serous and mucinous ovarian epithelial tumors. Pathol Int. 2009;59:300-5.

34. Lan C, Huang X, Lin S, Huang H, Cai Q, Wan T, Lu J, Liu J. Expression of M2-polarized macrophages is associated with poor prognosis for advanced epithelial ovarian cancer. Technol Cancer Res Treat. 2013;12:259-67.

35. Aymeric L, Apetoh L, Ghiringhelli F, Tesniere A, Martins I, Kroemer G, Smyth MJ, Zitvogel L. Tumor cell death and ATP release prime dendritic cells and efficient anticancer immunity. Cancer Res. 2010;70:855-8.

36. Ferrari D, Chiozzi P, Falzoni S, Dal Susino M, Melchiorri L, Baricordi OR, Di Virgilio F. Extracellular ATP triggers IL-1 beta release by activating the purinergic P2Z receptor of human macrophages. J Immunol. 1997;159: $1451-8$

37. Idzko M, Hammad H, van Nimwegen M, Kool M, Willart MA, Muskens F, Hoogsteden HC, Luttmann W, Ferrari D, Di Virgilio F, et al. Extracellular ATP triggers and maintains asthmatic airway inflammation by activating dendritic cells. Nat Med. 2007;13:913-9.

38. Khakh BS, North RA. P2X receptors as cell-surface ATP sensors in health and disease. Nature. 2006:442:527-32.

39. Cekic C, Day YJ, Sag D, Linden J. Myeloid expression of adenosine A2A receptor suppresses $t$ and $n k$ cell responses in the solid tumor microenvironment. Cancer Res. 2014;74:7250-9.

40. Ryzhov S, Novitskiy SV, Goldstein AE, Biktasova A, Blackburn MR, Biaggioni I, Dikov MM, Feoktistov I. Adenosinergic regulation of the expansion and immunosuppressive activity of CD11b + Gr1+ cells. J Immunol. 2011;187: 6120-9.

41. Zanin RF, Braganhol E, Bergamin LS, Campesato LF, Filho AZ, Moreira JC, Morrone FB, Sevigny J, Schetinger MR, de Souza Wyse AT, Battastini AM. Differential macrophage activation alters the expression profile of NTPDase and ecto-5'-nucleotidase. PLoS One. 2012;7:e31205.

42. Gyorffy B, Lanczky A, Szallasi Z. Implementing an online tool for genomewide validation of survival-associated biomarkers in ovarian-cancer using microarray data from 1287 patients. Endocr Relat Cancer. 2012;19:197-208.

43. Hagemann T, Wilson J, Burke F, Kulbe H, Li NF, Pluddemann A, Charles K, Gordon S, Balkwill FR. Ovarian cancer cells polarize macrophages toward a tumor-associated phenotype. J Immunol. 2006;176:5023-32.

44. Wang YC, He F, Feng F, Liu XW, Dong GY, Qin HY, Hu XB, Zheng MH, Liang L, Feng $L$, et al. Notch signaling determines the M1 versus M2 polarization of macrophages in antitumor immune responses. Cancer Res. 2010;70:4840-9.

45. Häusler SF, Ossadnik M, Horn E, Heuer S, Dietl J, Wischhusen J. A cell-based luciferase-dependent assay for the quantitative determination of free extracellular adenosine with paracrine signaling activity. J Immunol Methods. 2010:361:51-6.

46. Chepurny OG, Holz GG. A novel cyclic adenosine monophosphate responsive luciferase reporter incorporating a nonpalindromic cyclic adenosine monophosphate response element provides optima performance for use in $\mathrm{G}$ protein coupled receptor drug discovery efforts. J Biomol Screen. 2007;12:740-6.

47. Talmadge JE, Gabrilovich DI. History of myeloid-derived suppressor cells. Nat Rev Cancer. 2013;13:739-52.

48. Chen HW, Chen HY, Wang LT, Wang FH, Fang LW, Lai HY, Chen HH, Lu J, Hung MS, Cheng Y, et al. Mesenchymal stem cells tune the development of monocyte-derived dendritic cells toward a myeloid-derived suppressive phenotype through growth-regulated oncogene chemokines. J Immunol. 2013;190:5065-77

49. Smith DF, Galkina E, Ley K, Huo Y. GRO family chemokines are specialized for monocyte arrest from flow. Am J Physiol Heart Circ Physiol. 2005;289:H1976-1984.

50. Chang Cl, Liao JC, Kuo L. Macrophage arginase promotes tumor cell growth and suppresses nitric oxide-mediated tumor cytotoxicity. Cancer Res. 2001;61:1100-6.

51. Elliott MR, Chekeni FB, Trampont PC, Lazarowski ER, Kadl A, Walk SF, Park D, Woodson Rl, Ostankovich M, Sharma P, et al. Nucleotides released by apoptotic cells act as a find-me signal to promote phagocytic clearance. Nature. 2009;461:282-6.

52. Ghiringhelli F, Apetoh $L$, Tesniere A, Aymeric L, Ma Y, Ortiz C, Vermaelen K, Panaretakis T, Mignot $G$, Ullrich $E$, et al. Activation of the NLRP3 inflammasome in dendritic cells induces IL-1beta-dependent adaptive immunity against tumors. Nat Med. 2009;15:1170-8.

53. Shi J, Wan Y, Di W. Effect of hypoxia and re-oxygenation on cell invasion and adhesion in human ovarian carcinoma cells. Oncol Rep. 2008;20:803-7

54. Hoskin DW, Mader JS, Furlong SJ, Conrad DM, Blay J. Inhibition of T cell and natural killer cell function by adenosine and its contribution to immune evasion by tumor cells (Review). Int J Oncol. 2008;32:527-35.

55. Stagg J, Divisekera U, McLaughlin N, Sharkey J, Pommey S, Denoyer D, Dwyer KM, Smyth MJ. Anti-CD73 antibody therapy inhibits breast tumor growth and metastasis. Proc Natl Acad Sci U S A. 2010;107:1547-52.

56. Loi S, Pommey S, Haibe-Kains B, Beavis PA, Darcy PK, Smyth MJ, Stagg J. CD73 promotes anthracycline resistance and poor prognosis in triple negative breast cancer. Proc Natl Acad Sci U S A. 2013;110:11091-6.

57. Oh HK, Sin Jl, Choi J, Park SH, Lee TS, Choi YS. Overexpression of CD73 in epithelial ovarian carcinoma is associated with better prognosis, lower stage, better differentiation and lower regulatory $T$ cell infiltration. J Gynecol Oncol. 2012;23:274-81.

58. Supernat A, Markiewicz A, Welnicka-Jaskiewicz M, Seroczynska B, Skokowski J, Sejda A, Szade J, Czapiewski P, Biernat W, Zaczek A. CD73 expression as a potential marker of good prognosis in breast carcinoma. Appl Immunohistochem Mol Morphol. 2012;20:103-7.

59. Wu XR, He XS, Chen YF, Yuan RX, Zeng Y, Lian L, Zou YF, Lan N, Wu XJ, Lan P. High expression of CD73 as a poor prognostic biomarker in human colorectal cancer. J Surg Oncol. 2012;106:130-7.

60. d'Almeida SM, Kauffenstein G, Roy C, Basset L, Papargyris L, Henrion D, Catros V, Ifrah N, Descamps P, Croue A, et al. The ecto-ATPDase CD39 is involved in the acquisition of the immunoregulatory phenotype by M-CSFmacrophages and ovarian cancer tumor-associated macrophages: Regulatory role of IL-27. Oncolmmunology 2016:e1178025. doi:10.1080/ 2162402X.

61. Laoui D, Van Overmeire E, Movahedi K, Van den Bossche J, Schouppe E, Mommer C, Nikolaou A, Morias Y, De Baetselier P, Van Ginderachter JA. Mononuclear phagocyte heterogeneity in cancer: different subsets and activation states reaching out at the tumor site. Immunobiology. 2011;216:1192-202.

62. Peranzoni E, Zilio S, Marigo I, Dolcetti L, Zanovello P, Mandruzzato S, Bronte $\mathrm{V}$. Myeloid-derived suppressor cell heterogeneity and subset definition. Curr Opin Immunol. 2010;22:238-44.

63. Kaufmann A, Musset B, Limberg SH, Renigunta V, Sus R, Dalpke AH, Heeg KM, Robaye B, Hanley PJ. "Host tissue damage" signal ATP promotes nondirectional migration and negatively regulates toll-like receptor signaling in human monocytes. J Biol Chem. 2005;280:32459-67.

64. Goepfert C, Sundberg C, Sevigny J, Enjyoji K, Hoshi T, Csizmadia E, Robson $\mathrm{S}$. Disordered cellular migration and angiogenesis in cd39-null mice. Circulation. 2001;104:3109-15.

65. Rose FR, Hirschhorn R, Weissmann G, Cronstein BN. Adenosine promotes neutrophil chemotaxis. J Exp Med. 1988;167:1186-94

66. Cronstein BN, Daguma L, Nichols D, Hutchison AJ, Williams M. The adenosine/neutrophil paradox resolved: human neutrophils possess both $\mathrm{A} 1$ and $\mathrm{A} 2$ receptors that promote chemotaxis and inhibit $\mathrm{O} 2$ generation, respectively. J Clin Invest. 1990;85:1150-7.

67. Grandoch M, Hoffmann J, Rock K, Wenzel F, Oberhuber A, Schelzig H, Fischer JW. Novel effects of adenosine receptors on pericellular hyaluronan matrix: implications for human smooth muscle cell phenotype and interactions with monocytes during atherosclerosis. Basic Res Cardiol. 2013;108:340.

68. Ferrari D, McNamee EN, Idzko M, Gambari R, Eltzschig HK. Purinergic signaling during immune cell trafficking. Trends Immunol. 2016;37:399-411.

69. Choi IY, Lee JC, Ju C, Hwang S, Cho GS, Lee HW, Choi WJ, Jeong LS, Kim WK. A3 adenosine receptor agonist reduces brain ischemic injury and inhibits inflammatory cell migration in rats. Am J Pathol. 2011;179:2042-52.

70. Hofer S, Ivarsson L, Stoitzner P, Auffinger M, Rainer C, Romani N, Heufler C. Adenosine slows migration of dendritic cells but does not affect other aspects of dendritic cell maturation. J Invest Dermatol. 2003:121:300-7.

71. Sundstrom $P$, Stenstad $H$, Langenes $V$, Ahlmanner $F$, Theander $L$, Ndah TG, Fredin K, Borjesson L, Gustavsson B, Bastid J, Quiding-Jarbrink M. Regulatory T cells from colon cancer patients inhibit effector T-cell migration through an adenosine-dependent mechanism. Cancer Immunol Res. 2016:4:183-93. 
72. Forte G, Sorrentino R, Montinaro A, Luciano A, Adcock IM, Maiolino P, Arra C, Cicala C, Pinto A, Morello S. Inhibition of CD73 improves B cell-mediated anti-tumor immunity in a mouse model of melanoma. J Immunol. 2012:189:2226-33.

73. Enjyoji K, Kotani K, Thukral C, Blumel B, Sun X, Wu Y, Imai M, Friedman D Csizmadia E, Bleibel W, et al. Deletion of cd39/entpd1 results in hepatic insulin resistance. Diabetes. 2008;57:2311-20.

Submit your next manuscript to BioMed Central and we will help you at every step:

- We accept pre-submission inquiries

- Our selector tool helps you to find the most relevant journal

- We provide round the clock customer support

- Convenient online submission

- Thorough peer review

- Inclusion in PubMed and all major indexing services

- Maximum visibility for your research

Submit your manuscript at www.biomedcentral.com/submit 